\title{
HINDQUARTER AMPUTATION
}

\author{
H. A. Brittain, Norwich, Exgland
}

Gordon-Taylor described interinnomino-abdominal or hindquarter amputation as "one of the most colossal mutilations practised on the human frame." In 1934, in collaboration with Wiles, he reviewed all cases reported in the literature and showed that the mortality rate had been 60 per cent. In 1939, he reported eleven personal cases. Since that time the operation has been practised with increasing success. The first reports in American literature were in 1942 (Leighton) and 1943 (King and Steelquist). More recently twelve hindquarter amputations were reported by Beck and Bickel (1948) but curiously without any reference at all to the pioneer work of Gordon-Taylor whose personal series now totals thirty-three cases.

The operation is one of great magnitude and should be undertaken only after careful deliberation. There are still many surgeons who doubt whether it is ever justified, their

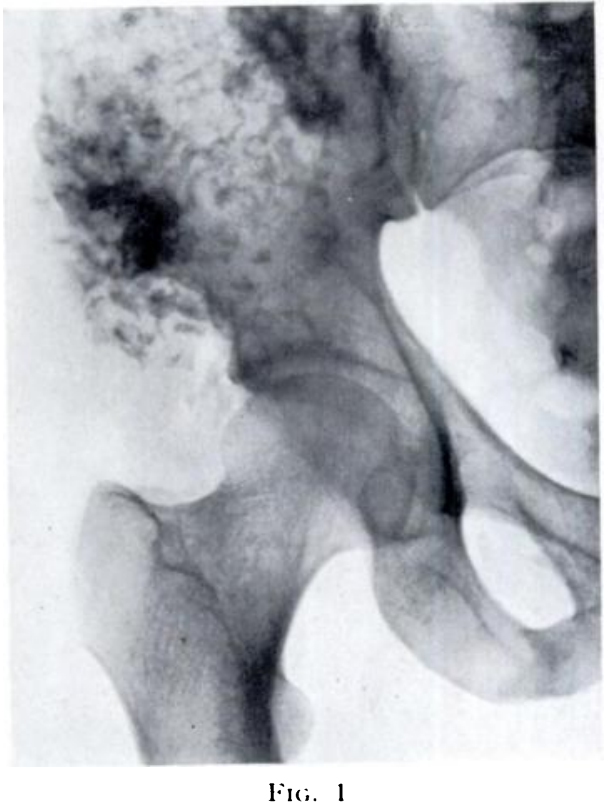

Case 1. W. I. Ossifying chondroma of the ilium, potentially malignant, reaching from the lower pole of the left kidney to the left hip joint. It was increasing steadily in size and, after a period of observation, hindquarter amputation was clearly inevitable. doubts being based not only on the slender chances of survival of patients whose hindquarters are amputated for malignant disease but also on the assumption that existence after such amputation must of necessity be miserable. It is the purpose of this paper, in recording five cases, to show that greater optimism may be justified and that the jors of life can still be indulged in despite the mutilation. It has even been possible to fit these patients with artificial limbs and teach them to walk without crutches. So far as is known this has not been recorded before.*

\section{CASE REPORTS}

Case 1. W. L., aged 42 years-First attended in 1938 with one year's history of swelling in the left iliac region extending to the hip-joint and the loin, steadily increasing in size. Radiographs suggested an ossifying chondroma of the ilium (Fig. 1). Biopsy supported the diagnosis of non-malignant ossifying chondroma. After one year the tumour was undoubtedly larger and was reaching up to the lower pole of the left kidney. In 1940 the patient had lost weight and did not look well. There was still no evidence of secondaries in the chest or elsewhere. After consultation with Sir Harry Platt, and examination of biopsy specimens by Professor Baker, it was agreed that hindquarter amputation was justified. This was done in June 1941. The operation was complicated by a urinary fistula which healed six months later. He is now alive and well, and has no complaints. He uses crutches and has adapted his life accordingly, and is unwilling to consider the fitting of an artificial limb.

Case 2. F. G., aged 26 years-First seen October 1945 when she gave a six months' history of a painful lump on the lateral aspect of the right thigh, increasing rapidly in size. Clinical examination showed a tumour of the right temur in the region of the greater trochanter. Open biopsy proved that it was a spindle-cell sarcoma (Fig. 2). Clinical and radiographic examination showed no evidence of secondary growths. Hindquarter amputation was performed December 1945. There was some sloughing of the upper part of the flap and oedema of the perineum but convalescence was otherwise uneventful (Figs. 5-7) . More skin than usual had been left in the posterior flap in the hope that it might prove possible to fit an artificial limb. A limb was fitted six months later in 1946 . The patient is still alive and well, and three and a half years after amputation is walking happily without crutches (Fig. 8).

* This paper a'as submitted for publication October 16, 1948. (See Editor's footnote at the cnd of the article.) It a'as read to the Boston Orthopaedic (lub, January 1949. 
Case 3. A. B., aged 42 years-First attended in Juiy 1947. Clinical examination showed Von Recklinghausen's neuro-fibromatosis. Complained of a painful lump on the antero-lateral aspect of the left thigh. During the previous two months the tumour had grown with increasing speed and begun to ulcerate. Biopsy showed evidence of an undifferentiated spindle cell sarcoma (Fig. 3). There was no clinical or radiographic evidence of secondary deposits. After hindquarter amputation convalescence was uneventful but three months later the patient died from massive secondary growths in the lungs.

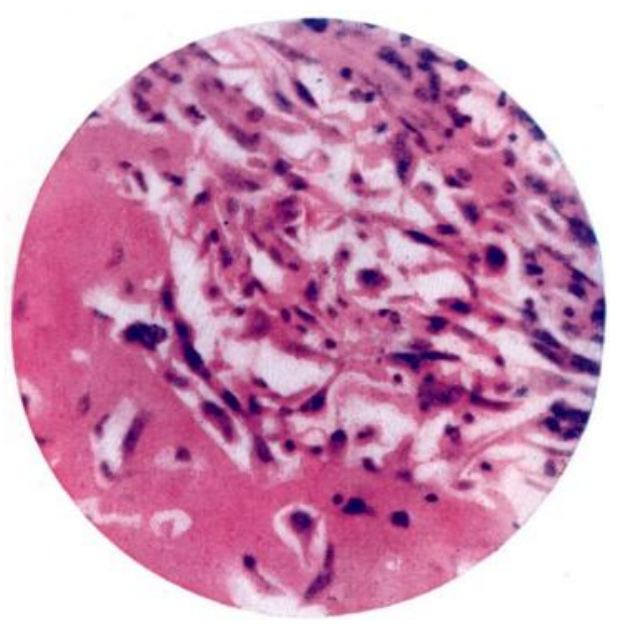

Fig. 2

Case 2. F. G. Spindle cell sarcoma-mass of tumour cells exhibiting pleomorphism: main cell type spindle; some giant and multinucliate forms; on the left side pink-staining homogeneous mass of osteoid tissue.

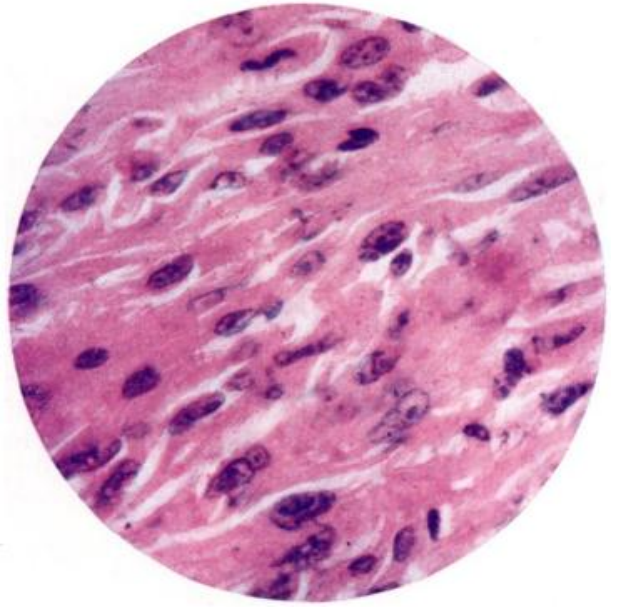

FIG. 3

Case 3. A. B. Spindle-cell sarcoma-closely packed mass of spindle-shaped cells; nuclei show alteration in size. Numerous mitotic figures and pleomorphism was seen in other sections.

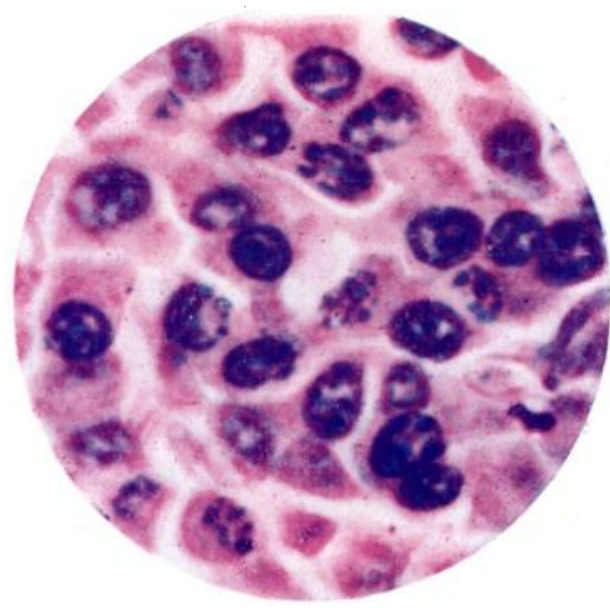

FIG. 4

Case 4. G. S. Plasmocrtoma-sheets of closely packed cells, some oval, some polygonal; characteristic appearance of plasma cells; nuclei most eccentric with chromatin in darkly staining clumps.

Case 4. G. S., aged 34 years-First seen July 18, 1947, when he gave a history of having slipped and strained his hip one week earlier. Radiographs showed a tumour of the upper end of the femur involving the greater trochanter with fracture through the lesser trochanter which was avulsed; the appearances suggested an osteoclastoma. Investigation of the family history showed that one sister died at the age of twenty-eight years from carcinoma of the breast, and another sister died at the age of thirty-six years from carcinoma of the uterus. After open biopsy it was reported that the tumour was a plasma-celled myeloma (plasmocytoma) (Fig. 4). After consultation with other pathologists and Mr Osmond-Clarke,

vol. $31 \mathrm{~B}$, No. 3, AUgust 1949 


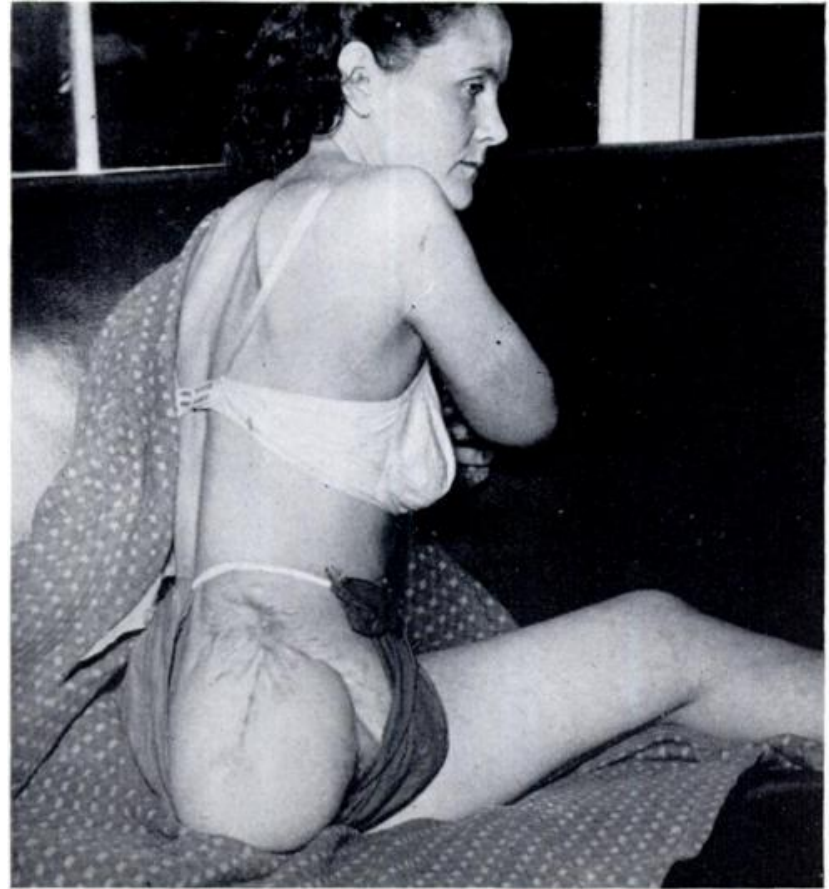

Fig. 5

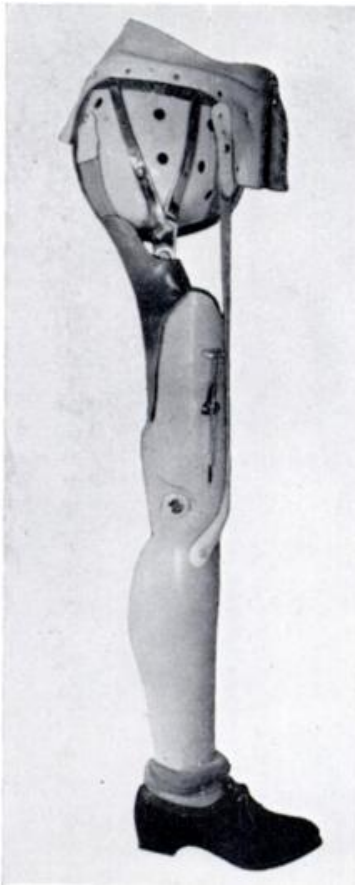

Fili. 6

Case 2. Patient with hindquarter amputation who walked with an artificial limb without crutches. Figure 6 shows the prosthesis, the socket being made to a cast of the stump and fitted with an automatic hip lock.

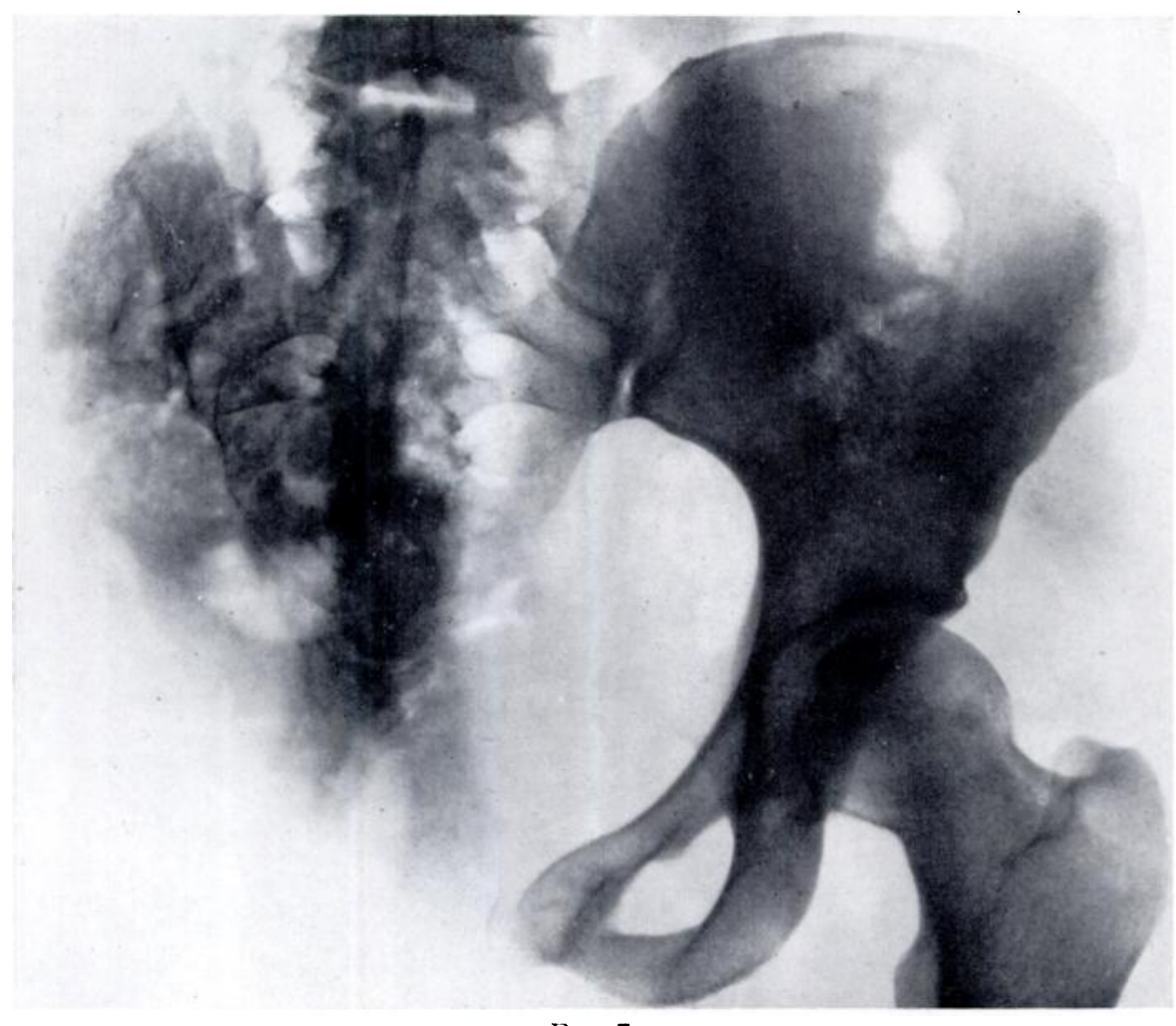

FIG. 7

Case 2. Radiograph after hindquarter amputation showing that no more than a small fragment of ilium remains. She walked with an artificial limb without crutches, weight-bearing being from the costal margin. 
hindquarter amputation was performed on December 5, 1947. There was pyrexia for some days but recovery was otherwise uneventful and the patient is still alive and well. He has been fitted with a prosthesis and is now walking and has discarded his crutches.

Case 5. G. W., aged 25 years-History of tuberculosis of the right hip joint with intermittent activity of disease since the age of five years. Three years ago ischio-femoral arthrodesis was attempted but failed owing to involvement of the graft by disease. The hip was unstable and there was four inches of true shortening. Many sinuses were discharging, two of them profusely. Radiographs showed extensive disease of both ilium and ischium with sequestration of the ischio-femoral graft. The patient's general condition was poor: there was a swinging temperature from 101 to 103 degrees; weight had gone down from eleven stone ( 154 pounds) to eight and a half stone ( 120 pounds); there had been many attacks of diarrhoea; the Congo red test for amyloid disease was positive; radiographs of the chest showed an early. active lesion in the right lung; haemoglobin was 52 per cent. After repeated blood transfusions the haemoglobin level rose to 82 per cent., and under the control of streptomy'cin, trans-iliac amputation was performed. Four pints of blood were transfused during and immediately after the operation. Nine months later the patient is alive and well.

Technique of operation-The operative technique described by Gordon-Taylor has been followed faithfully except that in Case 2 the common iliac artery was tied instead of the external iliac artery. This certainly made the operation easier but there was some sloughing in the anterior part of the flap. It is difficult to attribute sloughing of the anterior flap to such arterial ligation but nevertheless the possibility of massive sloughing after ligation of the common iliac artery must be recognised. The only other divergence from the technique originally described was that the ilium was cut through in a few seconds with hammer and chisel instead of with a Gigli saw. In the five cases here reported the operative time was ninety minutes, eighty minutes, eighty-two minutes, seventy-five minutes and sixty-five minutes respectively. It is interesting to compare these times with Gordon-Taylor's average time of sixty-five minutes and also with the four hours and forty minutes recorded by King and Steelquist for trans-iliac amputation. The importance of blood transfusion throughout the operation, as in all such major procedures, calls for no emphasis. Case 1 illustrates the danger of urinary fistula. It is believed that the injury in that patient was inflicted on the bladder at the time that the symphysis pubis was being divided. Special care must of course be taken to avoid damage to the ureters.

\section{THE FITTING OF ARTIFICIAL LIMBS TO HINDQUARTER AMPUTATIONS}

In the second case reported in this series, more skin than usual was left in the posterior flap in the hope that some form of prosthesis might be fitted. At that time, in 1946, the limb-fitting surgeons at Queen Mary's Hospital, Roehampton, thought that the fitting of an artificial limb was impracticable; but after consultation with $\mathrm{Mr} \mathrm{F}$. H. Powley of the Cambridge branch of Messrs Hanger \& Co., Ltd., a limb was fitted to this young widow who was determined to persevere despite the almost insuperable difficulties.

Mr Powley writes: "The latest type of artificial limb that has been supplied for disarticulation at the hip joint was fitted in this case, there being just enough hindquarter left to which a socket could be fitted with the necessary seating. A very careful cast was made of the pelvic stump on which the socket was made. The limb was so fitted that there was minimal movement as the patient propelled and rotated her pelvis in taking a forward step. The artificial limb attached to the socket was of light metal and had the latest improvements in mechanical detail and design, including an automatic hip lock. This kept the thigh rigid with the socket while the patient was walking; but by pressing a small button over the outer side of the hip joint she could tilt the socket forward and sit quite normally. On rising to walk, the hip lock engaged automatically. Success in this case was due largely to the determination of the patient by which she succeeded in making the fullest possible use of the artificial limb."

vol. $31 \mathrm{~B}$, No. 3 , AUgust 1949 

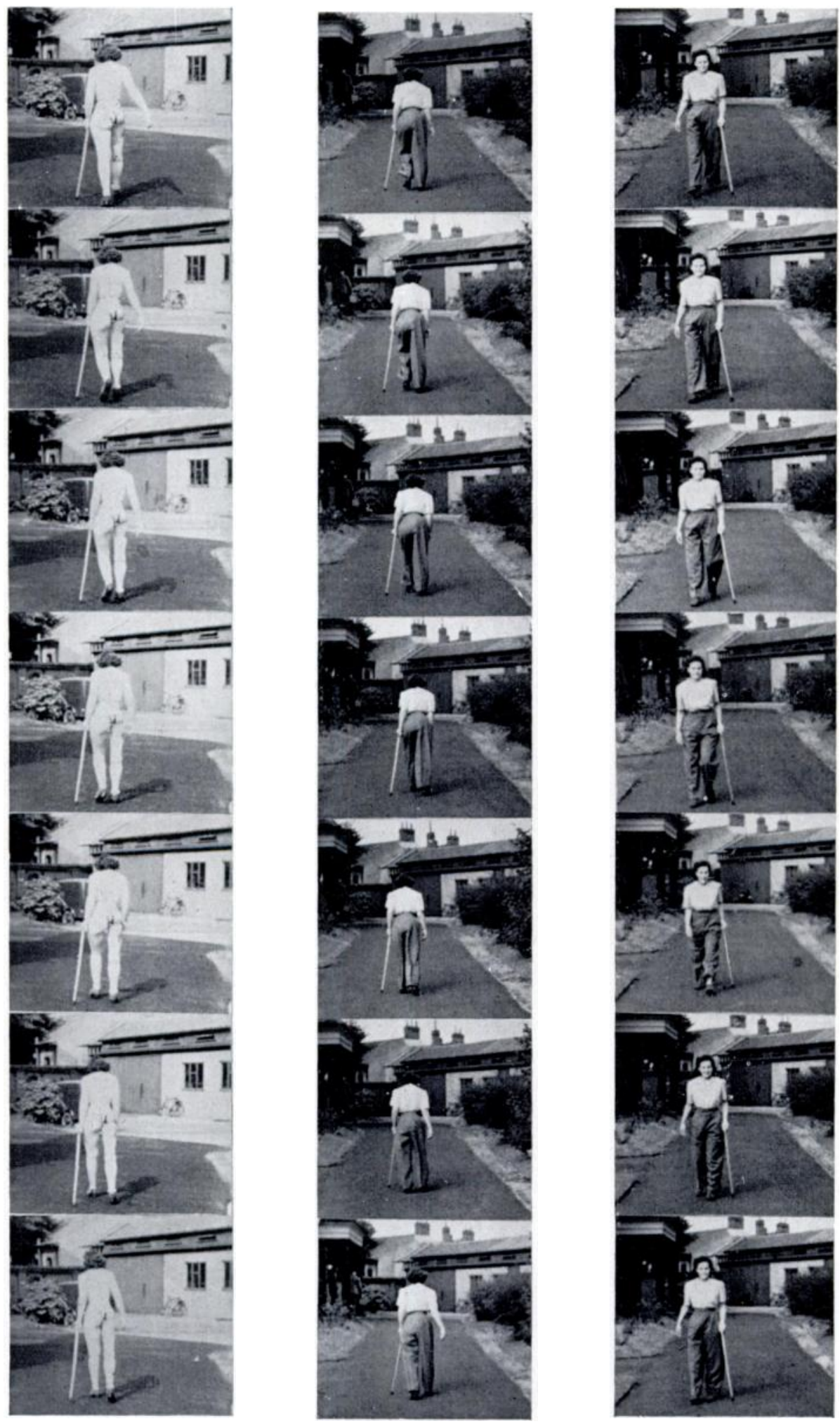

FIG. 8

Case 2. Reproduction from a ciné film showing patient walking with prosthesis, without crutches, after hindquarter amputation. 
Three and a half years later this patient reports that she is well, still wearing her artificial limb and attending to all household duties. She can walk half a mile without fatigue or pain (Fig. 8). It may well be asked: "On what is she walking?" We are aware of tibial-bearing in below-knee amputations and of ischial-bearing in below-knee and above-knee amputations. We recognise that it is possible to bear weight after disarticulation through the hip joint. But where is weight borne after hindquarter amputation? Radiographs show that in this particular case a small fragment of ilium remains lateral to the sacro-iliac joint but this does not provide a weight-bearing area (Fig. 7). There can be little doubt that most of the weight is taken on the ribs and lower thorax. As the patient takes weight on the artificial limb she inspires reflexly, holds her breath, and, being a thoracic-breather, thus fills the bucket of the limb.

This determined young woman was the first patient to my knowledge to walk without crutches on an artificial limb after hindquarter amputation. Others, in this small series of cases, have followed her example. There seems no reason why every patient who suffers hindquarter amputation should not learn to walk without crutches.

\section{REFERENCES}

Beck, N. R., and Bickel, W. H. (1948): Interinnomino-Abdominal Amputations: Report of Twelve Cases. Journal of Bone and Joint Surgery, 30 A, 201.

Ghormley, R, K., Henderson, M. S., and Lipscomb (1944): Interinnomino-Abdominal Amputation for Chondro-sarcoma and Extensive Chondroma: Report of Two Cases. Proceedings of Staff Meeting, Mayo Clinic, 19, 193.

Gordon-TAYlor, G., and Wiles, P. (1934): Interinnomino-Abdominal (Hindquarter) Amputation. British Journal of Surgery, 22, 671.

Gordon-TAYlor, G. (1939): A Further Review of the Interinnomino-Abdominal Operation: Eleven Personal Cases. British Journal of Surgery, 27, 643.

King, Don., and Steelouist, J. (1943): Trans-iliac Amputation. Journal Bone and Joint Surgery, 25, 351. Leighton, W. E. (1942): Interpelvi-abdominal Amputation: Report of Three Cases: Archives of Surgery, 45, 913,

Editor's Note-This paper was received for publication in October 1948 . Since then other examples have been reported of patients who have been fitted with artificial limbs and have learned to walk without crutches after hindquarter. amputation (Mitchell and Baird: British Medical Journal, November 1948, 2, 940; Wise, R. A.: Journal of Bone and Joint Surgery, April 1949, 31 A, 426). 